\title{
Supplementary material to: Seventeen years of ozone sounding at L'Aquila, Italy: evidence of mid-latitude stratospheric ozone recovery and tropospheric profile changes
}

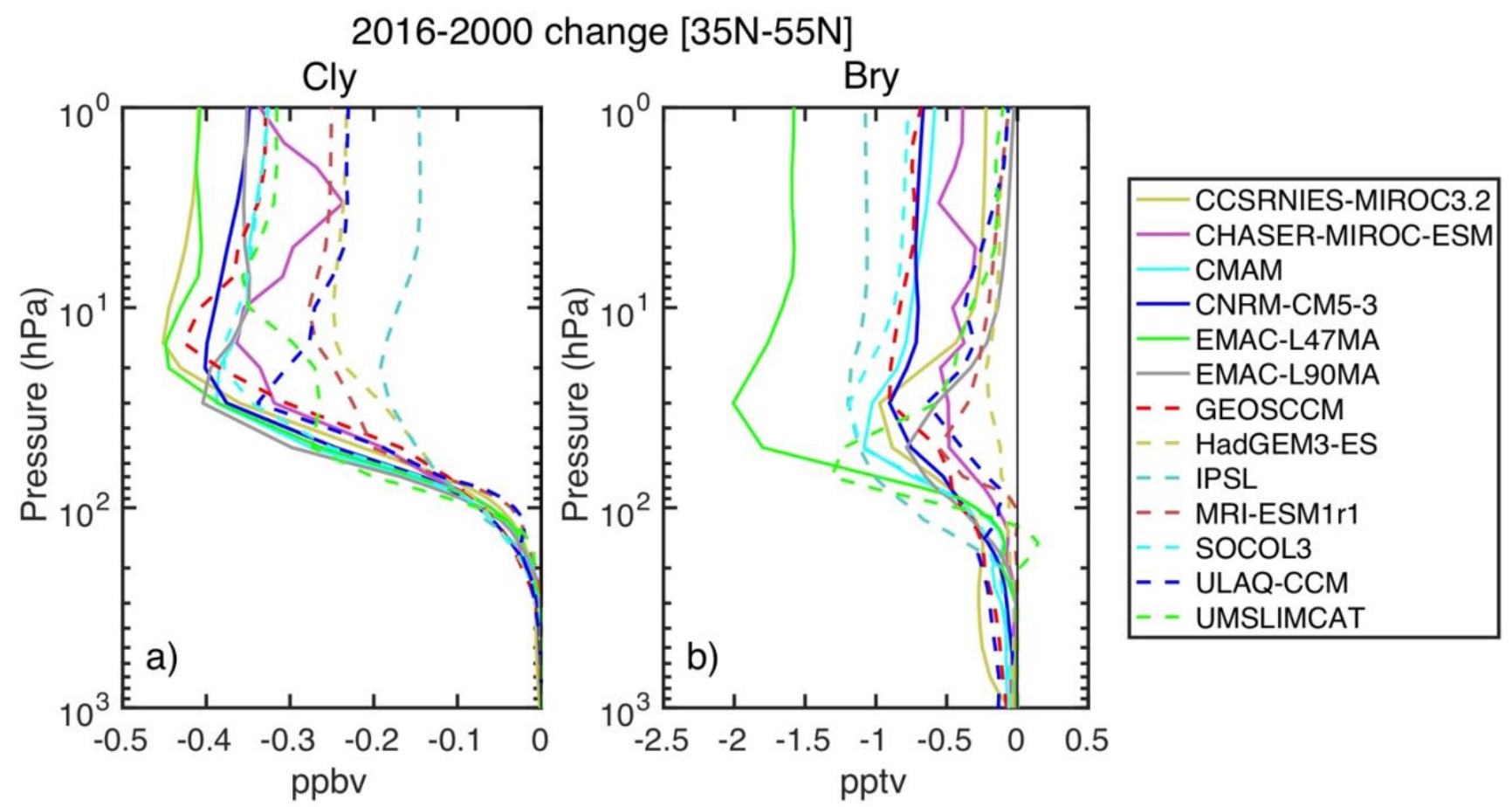

Fig. S1. Vertical profiles of northern mid-latitude changes $(35 \mathrm{~N}-55 \mathrm{~N})$ of total inorganic chlorine $(\mathrm{Cl}$, ppbv) (a) and total inorganic bromine (Bry, pptv) (b) for the single CCMI models that compose the multi-model means in Fig. 6cd. Changes are calculated as the difference of 2015-2016 mean values with respect to 1999-2000 mean values. 


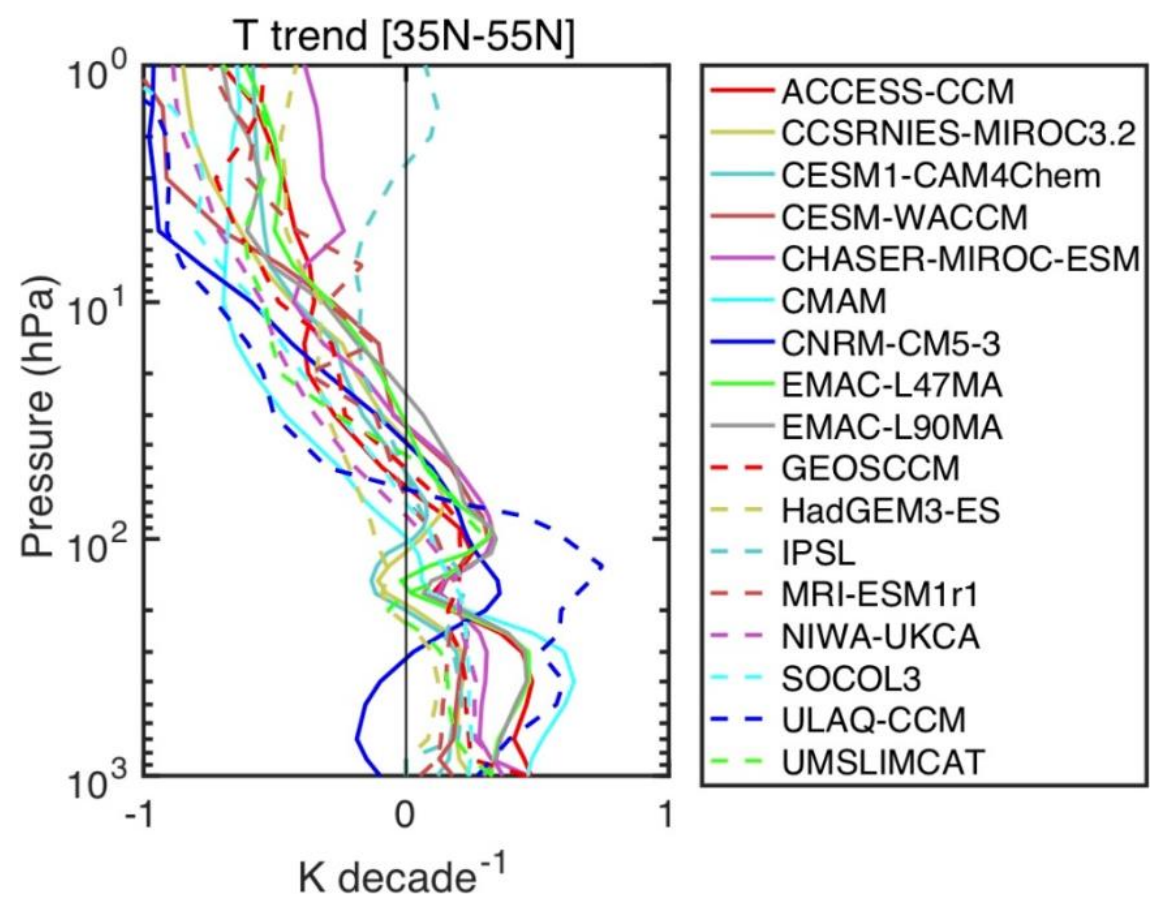

Fig. S2. Vertical profiles of northern mid-latitude linear trend $(35 \mathrm{~N}-55 \mathrm{~N})$ of air temperature (K/decade) for the single CCMI models that compose the multi-model mean in Fig. 7d. The trend is defined as the linear regression coefficient of the yearly mean of the single T profile values between 2000 and 2016.

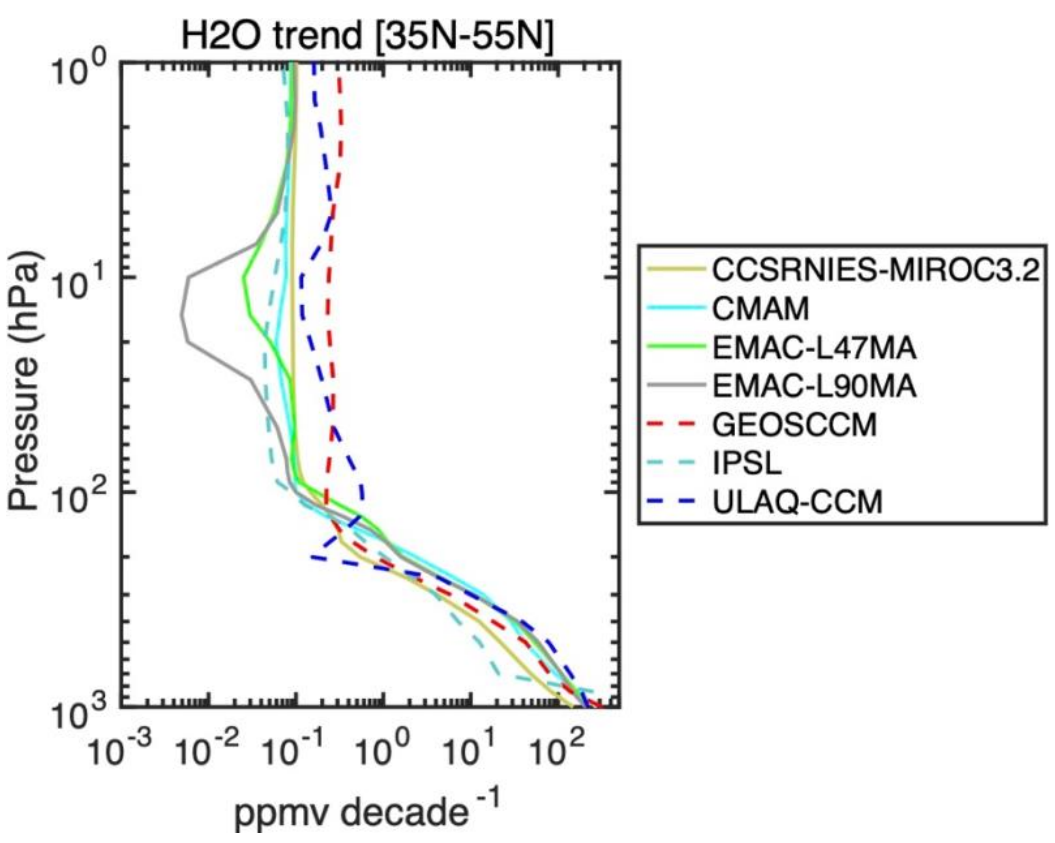

Fig. S3. Vertical profiles of northern mid-latitude linear trend $(35 \mathrm{~N}-55 \mathrm{~N})$ of water vapor (ppmv/decade) for the single CCMI models that compose the multi-model mean in Fig. 8a. The trend is defined as the linear regression coefficient of the yearly mean of the single $\mathrm{H}_{2} \mathrm{O}$ profile values between 2000 and 2016. 
$\mathrm{O}_{3}$ trend $(2000-2016)[35 \mathrm{~N}-55 \mathrm{~N}]$
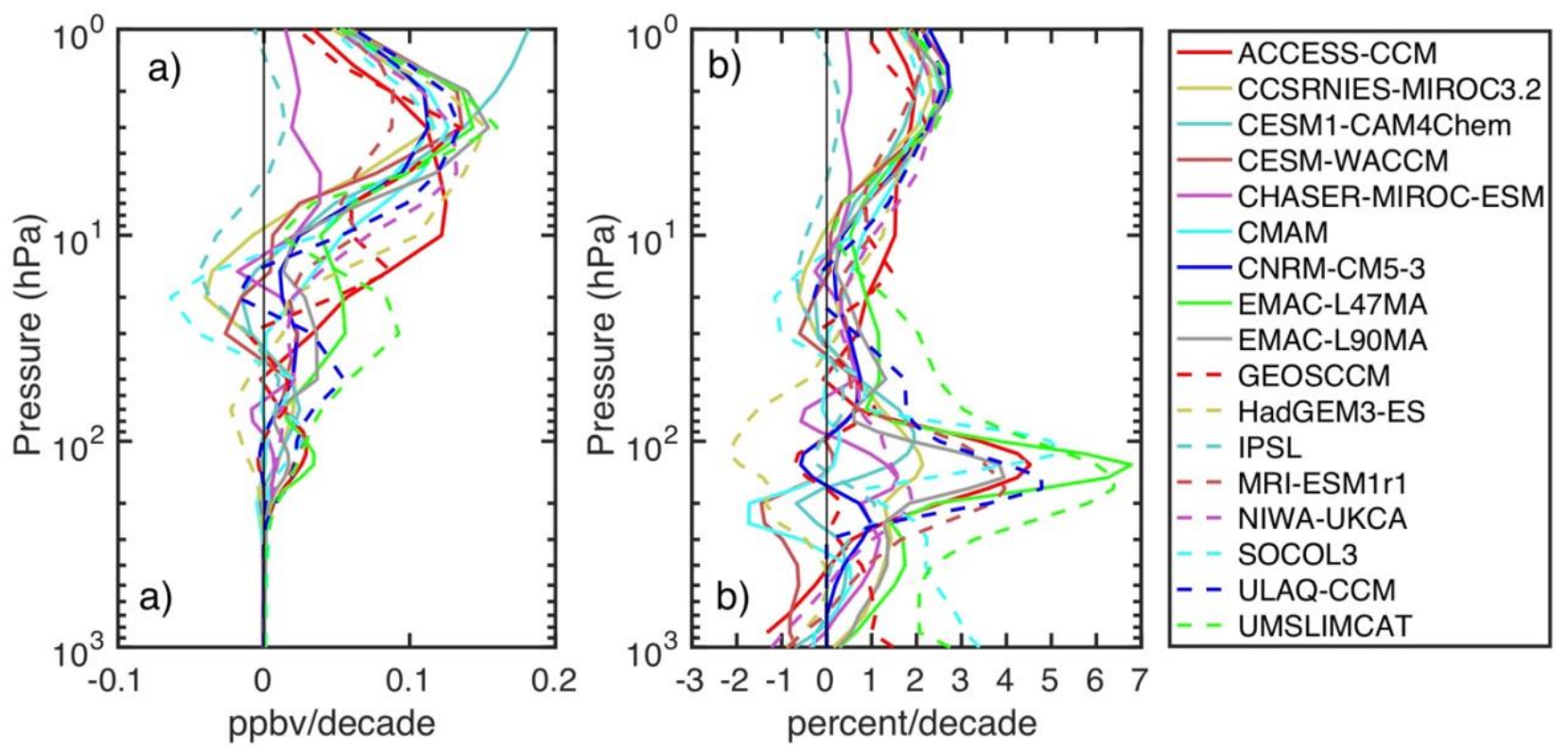

Fig. S4. Vertical profiles of northern mid-latitude linear trend $(35 \mathrm{~N}-55 \mathrm{~N})$ of ozone (a) ppbv/decade and (b) percent/decade, for the single CCMI models that compose the multi-model mean in Fig. 8bc. The trend is defined as the linear regression coefficient of the yearly mean of the single $\mathrm{O}_{3}$ profile values between 2000 and 2016. 
Ozone vertical fluxes [10-100 hPa, 35N-55N]
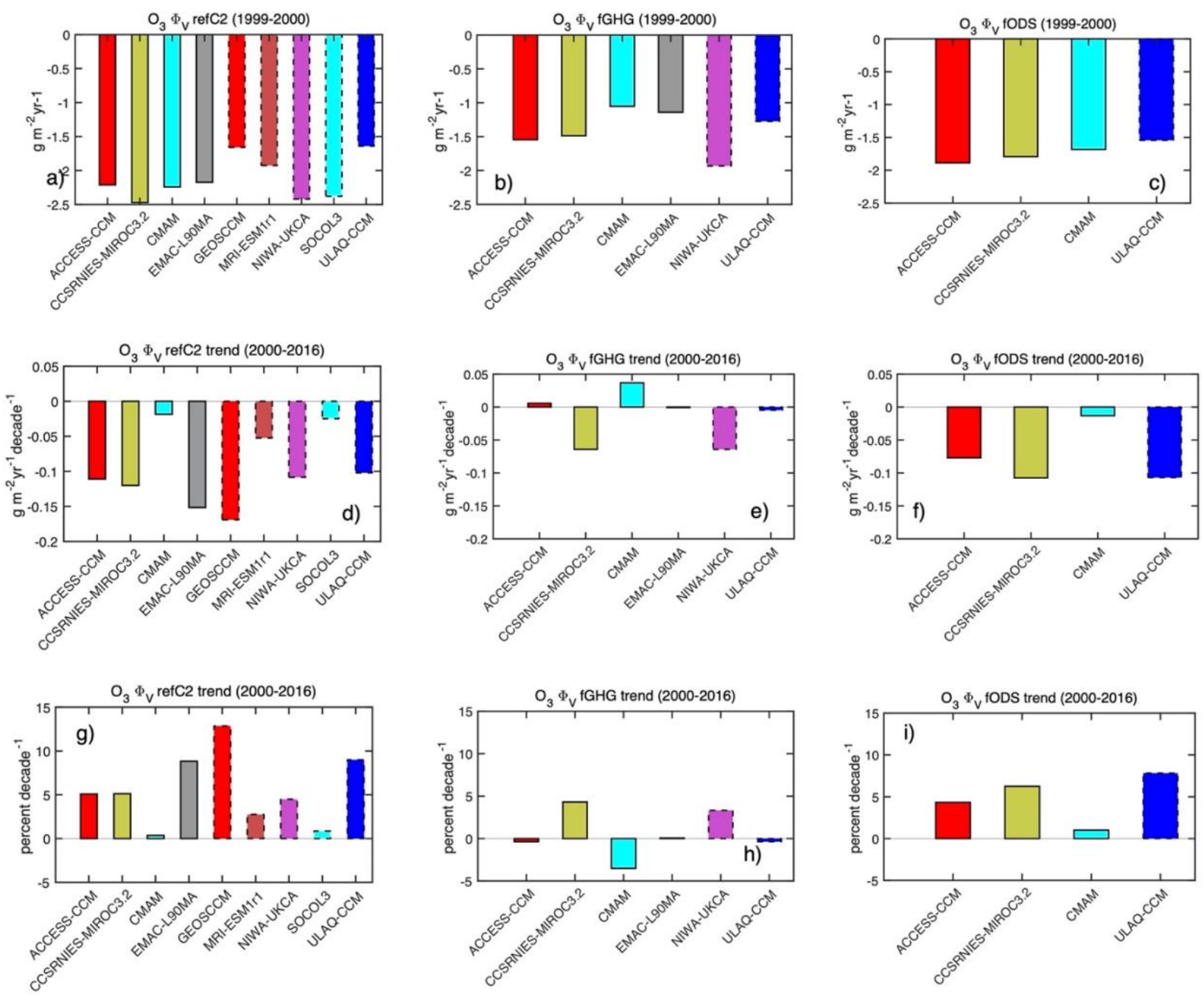

Fig. S5. Mid-latitude lower stratospheric vertical fluxes $\left(\mathrm{g} / \mathrm{m} 2 / \mathrm{yr}\right.$ ) of $\mathrm{O}_{3}(1999-2000)$ for $\mathrm{refC} 2$ (panel a), fGHG (panel b) and fODS (panel c) for all available models. Linear trend ( $\mathrm{g} / \mathrm{m} 2 / \mathrm{yr} / \mathrm{dec}$ de) of the LS vertical fluxes of $\mathrm{O}_{3}$ between 2000 and 2016 for refC2 (panel c), fGHG (panel d) and fODS (panel e). Last three panels are like the middle ones, but expressed in $\%$ of the fluxes in panel a), b) and c). The averaged values are shown in Fig. 9. The trend is defined as the linear regression coefficient of the yearly mean of the vertical fluxes between 2000 and 2016. 


\section{Ozone horizontal fluxes [10-100 hPa, 35N-55N]}
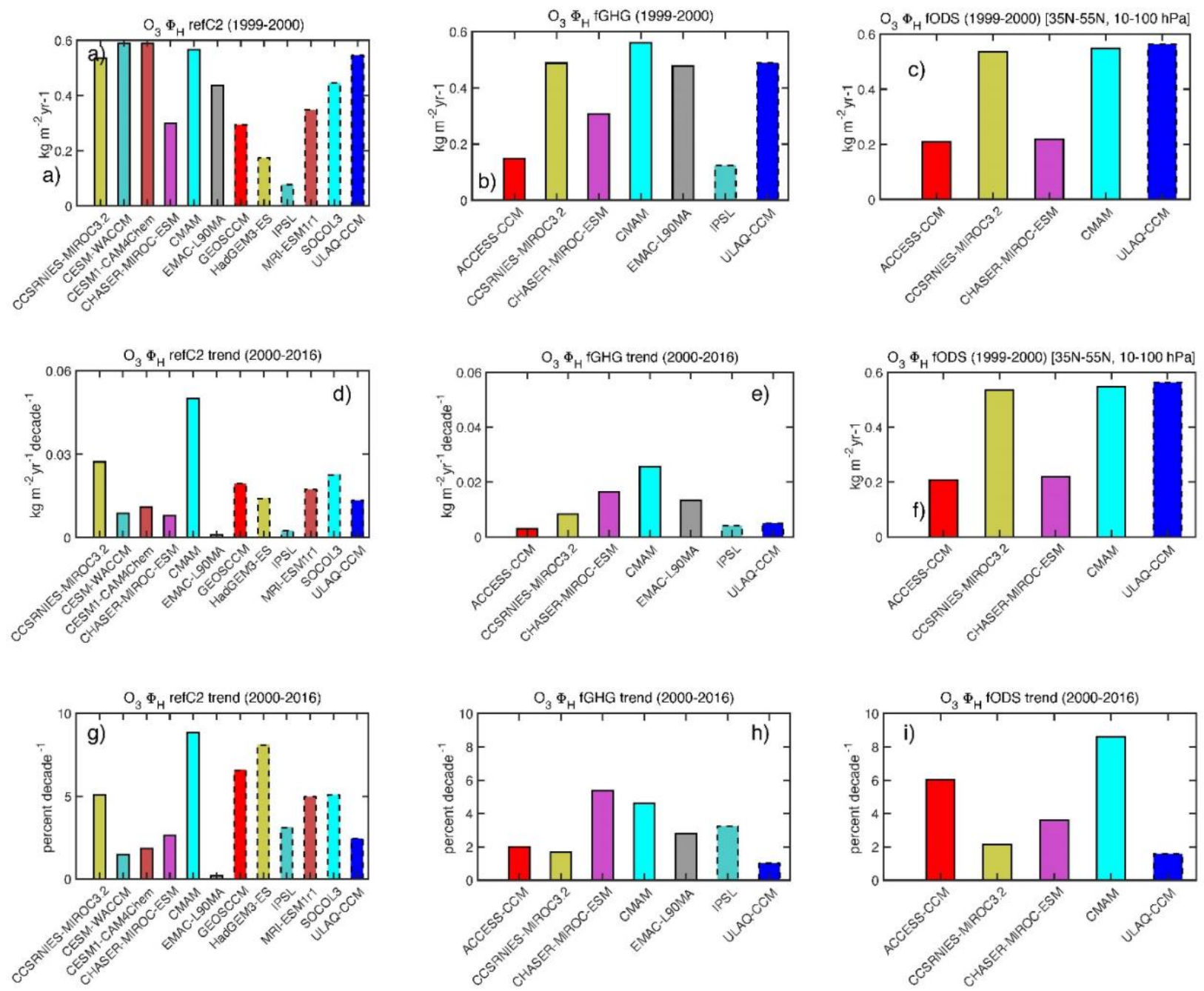

Fig. S6. Mid-latitude lower stratospheric horizontal fluxes $(\mathrm{kg} / \mathrm{m} 2 / \mathrm{yr})$ of $\mathrm{O}_{3}$ (1999-2000) for refC2 (panel a), fGHG (panel b) and fODS (panel c) for all available models. Linear trend ( $\mathrm{g} / \mathrm{m} 2 / \mathrm{yr} / \mathrm{decade}$ ) of the LS horizontal fluxes of $\mathrm{O}_{3}$ between 2000 and 2016 for refC2 (panel c), fGHG (panel d) and fODS (panel e). Last three panels are like the middle ones, but expressed in \% of the fluxes in panel a), b) and c). The averaged values are shown in Fig. 9. The trend is defined as the linear regression coefficient of the yearly mean of the vertical fluxes between 2000 and 2016. 

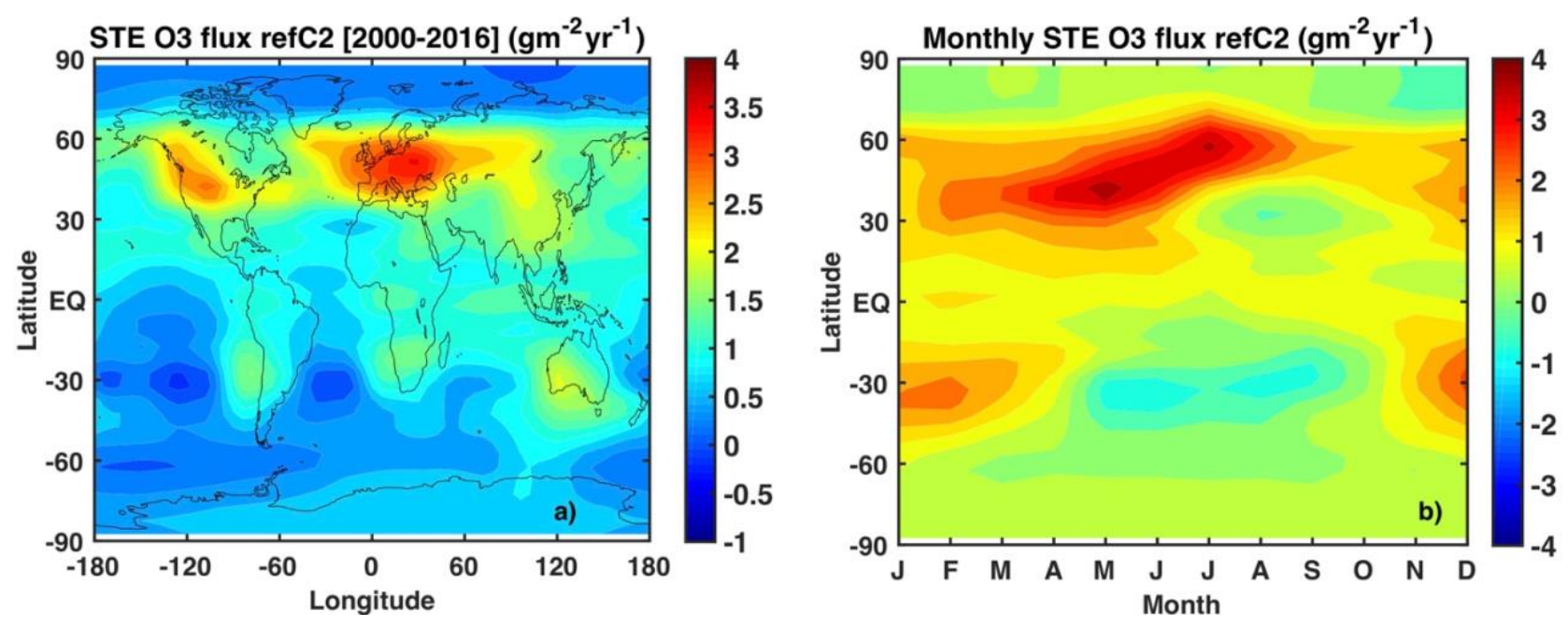

Fig. S7. a) Map of the $\mathrm{STE}_{3}$ flux in refC2 (g/m2/yr) averaged over the years 2000-2016. b) Zonally averaged monthly STE $\mathrm{O}_{3}$ flux in refC2 (g/m2/yr) averaged over the years 2000-2016 for the ULAQCCM model. 